\title{
Diagnóstico diferencial de dor abdominal na infância: relato de um caso
} Differential diagnosis of abdominal pain in childhood: a case report

Gabriela Moreira de Toledo ${ }^{1}$, Karine Guimarães Lacerda ${ }^{1}$, Luciana Cristina Viera dos Santos ${ }^{1}$, Maria Carolina Pereira da Rocha ${ }^{1}$

\begin{abstract}
RESUMO
Dor abdominal aguda é uma das principais queixas pediátricas com vários diagnósticos diferenciais. Paciente de dois anos e oito meses, do sexo feminino, negra, natural de Itapeva, São Paulo. Referia dor abdominal, diarreia e tosse havia 16 dias. Foi internada com hipótese diagnóstica de pneumonia. Durante a internação apresentou tosse, gemência, desconforto respiratório, vômitos, diarreia, distensão abdominal e febre. A má evolução do quadro e a piora da dor abdominal levaram à realização de uma tomografia abdominal que revelou apendicolitos. Foi encaminhada ao serviço de referência, onde houve a suspeita de apendicite aguda e foi realizada intervenção cirúrgica. O diagnóstico conclusivo foi de apendicite aguda purulenta. A paciente evoluiu dentro do esperado e teve alta dez dias após a cirurgia. Numerosos distúrbios podem causar dor abdominal; as causas mais comuns são gastroenterite e apendicite; porém, outros diagnósticos diferenciais devem ser considerados, entre eles pneumonia. No caso relatado, apesar de a paciente estar inicialmente taquidispneica, apresentava dor abdominal intensa e desidratação. Uma boa anamnese é fundamental. As alterações laboratoriais são inespecíficas e ocorrerem nos dois casos. Diante de um quadro de pneumonia com má evolução, é importante pensar na possibilidade de outro diagnóstico, entre eles apendicite, se o quadro vier acompanhado de dor abdominal, devido à sua alta morbimortalidade.
\end{abstract}

Palavras-chave: dor abdominal; apendicite; pneumonia; doença aguda; diagnóstico diferencial; criança.

\begin{abstract}
Acute abdominal pain is a major pediatric complain with a wide range of differential diagnoses. Pacient was two years and eight months, female, black, born in Itapeva, São Paulo, Brazil. She referred abdominal pain, diarrhea and cough for 16 days. She was hospitalized with a diagnosis of pneumonia. During hospitalization, she presented coughing, grunting, respiratory distress, vomiting, diarrhea, abdominal distension and fever. The bad evolution and worsening abdominal pain led to an abdominal tomography, which revealed appendix fecal calcifications. She was taken to the reference service, where there was suspicion of acute appendicitis and then surgery was performed. The final diagnosis was acute purulent appendicitis. The patient progressed as expected and was discharged ten days after surgery. Numerous disorders can cause abdominal pain; the most common causes are gastroenteritis and appendicitis. However, other differential diagnosis should be considered, including pneumonia. In the case reported, although the patient was initially tachydyspneic, she had severe abdominal pain and dehydration. A good medical history is essential. Laboratory abnormalities are nonspecific and occur in both cases. In cases in which pneumonia progresses with poor outcome, it is important to think about the possibility of another diagnosis, including appendicitis, if the complains include abdominal pain, due to its high morbidity and mortality.
\end{abstract}

Keywords: abdominal pain; appendicitis; pneumonia; acute disease; diagnosis, differential; child.

\section{INTRODUÇÃO}

A dor abdominal aguda é geralmente autolimitada, benigna, como por exemplo, nas gastroenterites, na constipação ou nas viroses. No entanto, o desafio médico está na busca e identificação de crianças com sintomas incomuns e possivelmente fatais que necessitem de abordagem e tratamento de urgência decorrentes de apendicite, intussuscepção, volvo e aderências. A frequência de intervenção cirúrgica em pacien- tes com esse quadro é de aproximadamente $1 \%$. Infelizmente, um grande número de pacientes não recebe um diagnóstico definitivo na primeira avaliação, pois os estágios iniciais de algumas doenças podem ser sutis ou atípicos. ${ }^{1}$

A dor é uma das manifestações mais precoces da enfermidade ou da lesão tecidual. A dor abdominal pode ser classificada como visceral, somatopariteal e referida, dependendo da natureza dos receptores de dor envolvidos.

'Pontifícia Universidade Católica de São Paulo, Faculdade de Ciências Médicas e da Saúde - Sorocaba (SP), Brasil.

Contato: karineg.1@ hotmail.com

Recebido em 03/05/2016. Aceito para publicação em 08/03/2017. 
A maioria das dores abdominais está relacionada com os receptores viscerais. ${ }^{1,2}$

Os receptores viscerais de dor estão localizados na membrana serosa, no mesentério, entre os músculos e a mucosa dos órgãos ocos, e respondem a estímulos mecânicos e químicos, como distensão, tensão e isquemia. Dado que as fibras nervosas viscerais não são mielinizadas e entram na medula lateralmente em diferentes níveis, a dor visceral tende a ser mal localizada, sem um ponto específico. ${ }^{1}$

A avaliação do paciente com dor abdominal aguda utiliza como instrumento a história, que valoriza dados referentes a dor, fatores associados à presença de vômitos, alteração do hábito intestinal e antecedentes mórbidos pessoais. A idade é um fator-chave para a avaliação da causa, pois a incidência dos sintomas das diferentes doenças varia de forma significativa de acordo com a faixa etária. Além disso, a dor abdominal apresenta-se como um sintoma de difícil caracterização, principalmente em lactentes e crianças pequenas, já que depende dos dados fornecidos pelos pais, que são influenciados pela sua capacidade de observação e por seu grau de angústia. ${ }^{2}$

\section{RELATO DE CASO}

Identificação: dois anos e oito meses, do sexo feminino, negra, natural e procedente de Itapeva, São Paulo.

Queixa e duração: dor abdominal, diarreia e tosse havia 16 dias.

História pregressa da moléstia atual (HPMA): mãe da paciente refere que há 16 dias a filha iniciou quadro de dor abdominal, acompanhada de diarreia e sibilância. Foi internada, na origem, com hipótese diagnóstica de broncopneumonia/broncoespasmo. Durante essa internação apresentou tosse, gemência, desconforto respiratório, vômitos, diarreia, distensão abdominal e febre. Ao longo da internação, mãe refere piora dos sintomas, com necessidade de passagem de sonda nasogástrica. Houve persistência da febre, em média quatro vezes ao dia, e piora dos sintomas abdominais. Desde o terceiro dia de internação estava em uso de vancomicina e meropenem. Como não houve resolução ou melhora do quadro, a paciente foi encaminhada para um hospital em Sorocaba como "vaga zero".

Constituição familiar: mãe, 20 anos, desempregada, sem comorbidades. Pai, 24 anos, presidiário, usuário de álcool e drogas. Irmão, cinco anos, teve anóxia neonatal, atualmente hígido.

Antecedentes familiares: sem comorbidades.

Condições domiciliares e socioeconômicas: residem em Itapeva, com a família da mãe, em casa com saneamento básico de água e esgoto. A mãe e os dois filhos dormem no mesmo cômodo.

Pré-natal: gestação sem intercorrências; mãe refere ter tido uma infecção urinária, tratada. Realizou pré-natal na unidade básica de saúde (UBS) desde o primeiro mês de gestação.

Natais: parto normal, idade gestacional de 34 semanas; peso de nascimento $2.450 \mathrm{~g}$, comprimento de $44 \mathrm{~cm}$. Mãe refere que criança não chorou ao nascer, mas não sabe Apgar. Perma- neceu em incubadora e unidade de terapia intensiva (UTI), com necessidade de oxigênio, mas sem intubação orotraqueal (IOT). Relata episódios de febre neonatais. Continuou sendo alimentada em seio materno, mãe nega uso de sonda nasogástrica. Não soube referir o tempo de internação exato.

Alimentares: aleitamento materno exclusivo até o sexto mês de vida. Introdução da papa de frutas e da refeição principal aos seis meses. Atualmente, a paciente prepara as refeições da família, que são bastante variadas e completas; toma leite de vaca integral.

Vacinação: imunizações estão em dia.

Crescimento e desenvolvimento: sem alterações.

Antecedentes mórbidos pessoais: teve anóxia neonatal, aparentemente sem repercussões graves. Com dois anos teve diagnóstico de bronquite. A mãe negou internações prévias.

Funcionamento intestinal: duas vezes ao dia, consistência pastosa, sem alterações.

\section{Exame físico de entrada}

- Regular estado geral, descorada $1+/+4$, hidratada, anictérica, acianótica, afebril, taquicárdica e taquipneica;

- Murmúrios vesiculares presentes bilateralmente sem ruídos adventícios, Frequência respiratória de 42 incursões respiratórias por minuto;

- Bulhas rítmicas normofonéticas a dois tempos, sem sopros, frequência cardíaca de $142 \mathrm{bpm}$;

- Abdome globoso, tenso à palpação, com aumento de temperatura ao toque; ruídos hidroaéreos ausentes; distensão abdominal não possibilitou a palpação profunda;

- Presença de pulsos filiformes; ausência de edema (Quadros 1 e 2).

Quadro 1. Exames laboratoriais da origem.

\begin{tabular}{|cccc|}
\hline Hb & 10,3 & PCR & 137,4 \\
\hline $\mathbf{H t}$ & $30,7 \%$ & TGO & 12 \\
\hline Leuco & 32,8 & TGP & 10 \\
\hline Plaquetas & $0 / 7 / 77 / 0 / 0 / 12 / 4$ & & \\
\hline
\end{tabular}

Hb: hemoglobina; Ht: hematócrito; Leuco: leucócitos; PCR: proteína c reativa; TGO: transaminase glutâmico oxalacética; TGP: transaminase glutâmico pirúvica.

Quadro 2. Exames laboratoriais de entrada.

\begin{tabular}{|cccc|}
\hline Hb & 11,2 & PCR & 203,9 \\
\hline Ht & $34,1 \%$ & TGO & 21 \\
\hline Leuco & 32,9 & TGP & 8 \\
\hline Plaquetas & $0 / 4 / 77 / 2 / 0 / 11 / 6$ & & \\
\hline
\end{tabular}

Hb: hemoglobina; Ht: hematócrito; Leuco: leucócitos; PCR: proteína c reativa; TGO: transaminase glutâmico oxalacética; TGP: transaminase glutâmico pirúvica. 
Raio-X de tórax na origem

- Trama vascular reforçada. Sem alterações.

\section{Tomografia computadorizada abdominal da origem}

- Hepatomegalia

- Discreta distensão de alças enterais

- Imagem cálcica ilíaca direta (apendicolito?)

- Linfonodos mesenterais

\section{Raio-X abdominal de entrada}

Raio-X abdominal em posição ortostática demonstrando aumento do espessamento da gordura pré-peritoneal. Nível hidroaéreo e ausência de ar no reto (Figura 1).

Avaliação Cirurgia Pediátrica (CIPE) na entrada: paciente vem encaminhada de outro serviço com quadro pulmonar interrogado em tratamento há 13 dias, sem melhora. Mãe refere que desde a internação a criança apresenta distensão e dor abdominal. Apresentou febre, náuseas e vômito nesse período. Havia evacuado no dia anterior. Ao exame apresenta abdome distendido e doloroso à palpação. Conduta: abordagem cirúrgica devido à apendicite complicada.

Laudo cirúrgico: laparotomia exploradora com achado de apendicite grau IV e grande quantidade de aderências; foram realizadas: sutura de lesão de alça durante lise de aderências, apendicectomia e drenagem de cavidade. Colocação de dois drenos de Penrose, um à direita e outro à esquerda, na região inguinal.

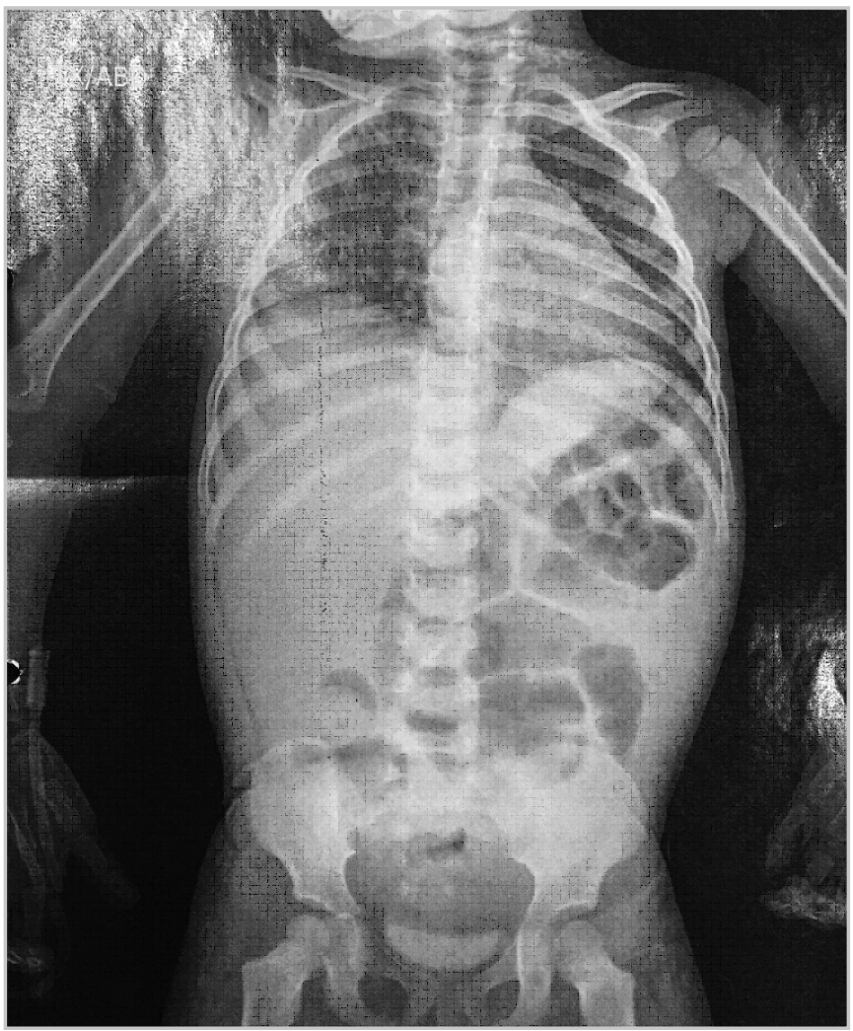

Figura 1. Raio-X abdominal (admissão do paciente).

\section{Raio-X abdominal pós-cirúrgico}

Raio-X abdominal em posição ortostática demonstrando recuperação de nível hidroaéreo em região inguinal direita (Figura 2).

\section{DISCUSSÃO}

A dor abdominal aguda como queixa em serviço de emergência pediátrica remete às causas mais comuns: gastroenterite e apendicite. Entre os diagnósticos diferenciais, pode-se citar adenite mesentérica, gastroenterite, obstipação, litíase renal, cisto ovariano, torção de ovário, gravidez ectópica, pneumonia de lobo direito, derrame pleural, cetoacidose diabética, infecção do trato urinário, tumor de Wilms e anemia falciforme. ${ }^{2}$

No caso relatado, a paciente apresentava sintomas de gastroenterite e quadro inicial compatível com apendicite, assim como queixas relacionadas à via respiratória. Havia alterações nos exames laboratoriais, com leucocitose e desvio à esquerda, aumento do número de plaquetas e da proteína $\mathrm{C}$ reativa. Pela ausência de melhora e visualização de apendicolitos à tomografia, suspeitou-se de apendicite, sendo feito encaminhamento ao serviço de referência. A paciente apresentava sinais de desconforto respiratório, mas os exames laboratoriais e o raio- $\mathrm{X}$ de tórax não confirmavam o diagnóstico de pneumonia. Apesar de taquidispneica, apresentava intensa dor abdominal e desidratação, o que contribui para essa descompensação, dissociando-se do suposto quadro respiratório.

A apendicite aguda constitui a principal afecção de abdômen agudo cirúrgico na criança com mais de dois anos de

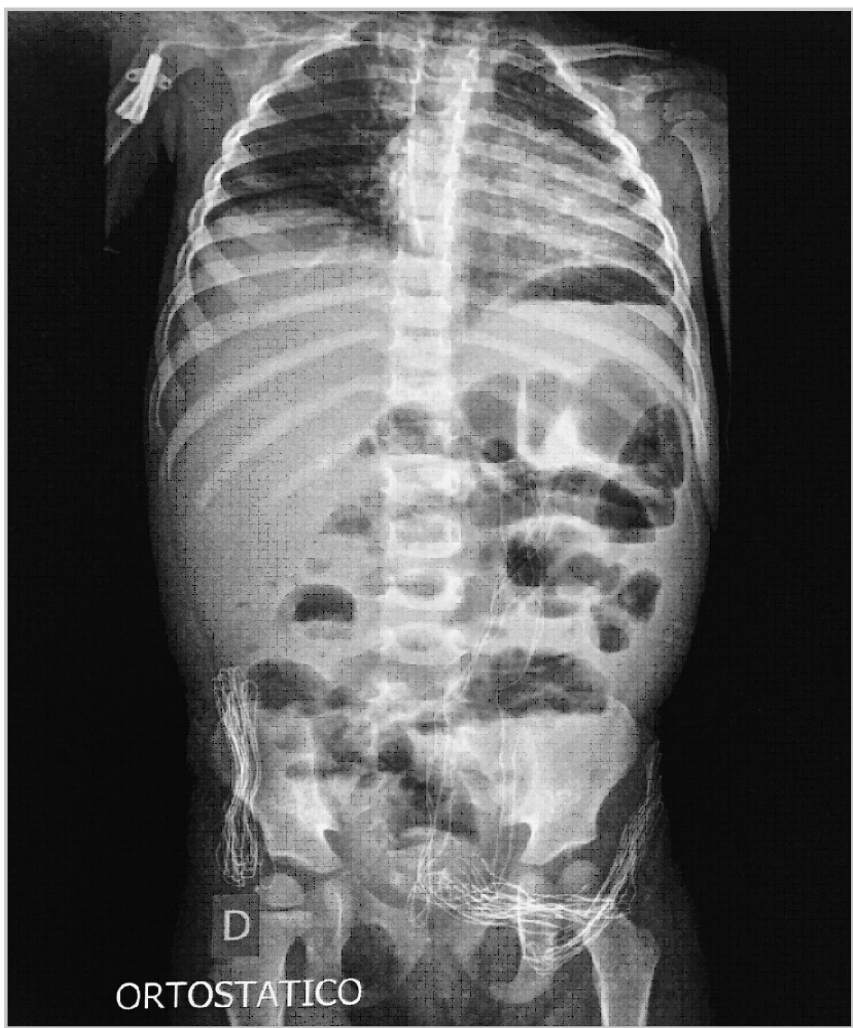

Figura 2. Raio-X abdominal após o tratamento cirúrgico. 
idade. Predomina na faixa etária dos 6 aos 18 anos. Há maior prevalência no sexo masculino, na proporção de 2:1.3.5 Aparece mais frequentemente em países industrializados com hábito alimentar pobre em fibras. ${ }^{6} \mathrm{O}$ principal desencadeante é a obstrução da luz intestinal, por fecalitos ou parasitas. ${ }^{7-9}$ O diagnóstico dessa doença na criança se baseia no quadro clínico. A dor abdominal insidiosa é inicialmente leve e mal localizada, no epigástrio ou na região periumbilical; posteriormente, tende a localizar-se no quadrante inferior direito do abdômen. Muitas vezes associada a vômitos e febre de baixa intensidade. Ao exame clínico, há presença de dor na fossa ilíaca ou no flanco direito; nos casos de peritonite difu$\mathrm{sa}$, verifica-se rigidez de parede abdominal. O quadro de irritação peritoneal pode ser demonstrado pelos sinais clássicos de Blumberg e Rovsing. ${ }^{6,9,10}$

Os exames subsidiários pouco ajudam para a confirmação diagnóstica. O hemograma geralmente revela uma leucocitose moderada e desvio à esquerda dos neutrófilos; valores maiores sugerem apendicites complicadas. A proteína $\mathrm{C}$ reativa está comumente aumentada, mas é pouco útil no diagnóstico. ${ }^{9}$ Os mais importantes são o ultrassom de abdômen e a tomografia computadorizada; atualmente sugere-se que o ultrassom seja solicitado apenas para crianças ou adolescentes do sexo feminino, para exclusão diagnóstica de afeç̧ões ovarianas ou prenhez ectópica rota. ${ }^{3}$

Diante da persistência da dor e ausência de definição diagnóstica, recomenda-se cirurgia exploradora. O diagnóstico, se tardio, predispõe a graves complicações, como peritonite, abscessos pélvicos ou subdiafragmáticos, obstrução intestinal e perfuração. ${ }^{6} \mathrm{~A}$ classificação laparoscópica da apendicite aguda em graus, de acordo com os achados inflamatórios, está diretamente relacionada ao prognóstico. Quanto maior, mais grave será e maior a necessidade de ampliar o espectro antimicrobiano. ${ }^{7}$ No caso relatado, a paciente foi classificada como grau IV, no qual há peritonite regional com possível necrose da base do apêndice. ${ }^{6}$ O tratamento consiste em: suspensão da dieta oral, hidratação venosa com reposição de líquidos (nos casos de vômito ou diarreia), analgesia, antibiótico endovenoso e cirurgia. ${ }^{8}$ É preferível iniciar com amicacina, uma vez realizado o diagnóstico de apendicite aguda, pode-se associar metronidazol e, em alguns casos, amoxicilina com clavulanato. Assim, procura-se eliminar os germes mais prevalentes Gram-negativos, os anaeróbicos e o Enterococcus. ${ }^{9}$

\section{CONCLUSÃO}

Diante de um quadro de pneumonia com má evolução, além de complicações ou erro na escolha dos antimicrobianos, é importante pensar na possibilidade de outro diagnóstico, entre eles apendicite, se o quadro vier acompanhado de dor abdominal. A atenção à possibilidade de apendicite é importante devido à alta morbimortalidade da doença, que é inversamente proporcional à velocidade com que o diagnóstico e a intervenção cirúrgica são feitos.

\section{REFERÊNCIAS}

1. Kim JS. Acute abdominal pain in children. Pediatr Gastroenterol Hepatol Nutr. 2013;16(4):219-24. DOI: 10.5223/pghn.2013.16.4.219

2. Martins SB. Brandão MA, Brandão $M B$, Reis $M C$, Servidone MF, Zambon MP. Diagnóstico pouco frequente de dor abdominal em unidade de emergência infantil. Rev Paul Pediatr. 2010;28(2):249-52.

3. Tannuri U. O surgimento dos métodos de imagem permitiu o diagnóstico mais precoce da apendicite aguda na criança? Rev Assoc Med Bras. 2003;49(4):356-7. DOI: $10.1590 /$ S0104-42302003000400014

4. Paiva MA, Reis FJ. Fisher GB, Rozov T. Pneumonias na criança. J Bras Pneumol. 1998;24(2):101-8.

5. Diretrizes brasileiras em pneumonia adquirida na comunidade em pediatria. J Bras Pneumol. 2007;33(Suppl1):31-50. DOI: 10.1590/S1806-37132007000700002

6. Vicente YA, Santos RO, Stracieri LDS, Sorita MFG, Pileggi FO. Urgências abdominais não traumáticas na criança. Rev Medicina (Ribeirão Preto). 1995;28(4):619-24.

7. Gomes CA, Nunes TA. Classificação laparoscópica da apendicite aguda: correlação entre graus da doença e as variáveis perioperatórias. Rev Col Bras Cir. 2006;33(5):289-93. DOI: 10.1590/S010069912006000500006

8. Tavares PB. Urgência em cirurgia pediátrica. Rev Pediatr SOPERJ. 2012;13(2):35-42.

9. Baratella JR, Sapucaia JR. Apendicite aguda. In: Campos Júnior D, Burns DA, Lopez F, Campos Júnior D. Tratado de pediatria; sociedade brasileira de pediatria. $3^{\text {a }}$ ed. São Paulo: Manole; 2014. p.3305-8.

10. Freitas RG, Pitombo MB, Maya MC, Leal PR. Abdome agudo não traumático: apendicite aguda. Rev Hosp Univ Pedro Ernesto UERJ. 2009;8(1):38-51. 